\title{
IT Governance Practices for The Success of IT Initiatives - A Conceptual Framework
}

\author{
Anusha Bhaskaran, Professor Dr Noor Ismawati Binti Jaafar \\ Faculty of Business and Economics, University of Malaya, Malaysia
}

\begin{abstract}
In the recent day, it is important to understand the ways to govern Information Technology in an organization rather than just utilizing them. IT Governance is critical to most of the organization. It acts more of a strategic driver for business rather than just a supportive tool. The overall performance of an organization can be impacted by IT Governance. IT Governance helps to specify the responsibilities to encourage a desirable behavior from IT to generate value from IT investments. Unfortunately, in many organizations, this is more of an aspiration than reality. The objective of this study is to explore the current practices of IT Governance in a manufacturing firm. This paper analyses the 3 main mechanisms of IT Governance, i.e., structure, process, and relational mechanisms, with relation to the main 5 domains of the IT Governance; IT value delivery, IT resource management, IT performance measurement, IT strategic alignment and IT risk management. This study is aligned with existing literatures on the concept of IT Governance and addresses the gap from a practical approach.
\end{abstract}

Key words: IT Governance, IT Governance three mechanisms, IT Governance Framework, IT Governance five domains, manufacturing firm

\section{INTRODUCTION}

A large amount of an organization's investment budget is spent on IT. It was reported that more than $50 \%$ of an organization's annual capital investment is spent on IT, which is greater than $4 \%$ of their annual revenue [1][2]. In another study conducted on more than 250 organizations globally, with the same type of competitive advantage, organizations with effective IT Governance are said to have at least $20 \%$ more profit compared to organizations thatdoes not have a very effective IT Governance [3]. The desired business value from the IT investment was not significant. In fact, for many organizations, the outcome of IT investments was negative [4]. This research shows that, with a well-managed IT Governance in place, important issues of an organization is paid-off as it is a concept developed to address IT business values [5]. The concept of IT Governance and IT Management varies. The former is not about the decisions made, which is more related to the IT Management. IT Governance is about determining who makes the decisions, the roles, responsibility, and their accountability [3]. It is not about managing IT directly but more related to organizing the IT Management. IT governance is practiced creating business values [6] and it is important to maximize the firm's growth and profit in terms of cost and asset utilization.

IT Governance have been introduced in many organizations; however, it is not very much practiced by the employees. Processes and tools that are introduced remains as a legacy and untouched for several years. Majority of the research conductedon how IT Governance should be organized, remains theoretical. There is also very less empirical research on how the organizations are governing their IT [7][8]. More than theoretical research, there is a need to conduct empirical research that would lead to a comprehensive investigation on IT Governance [9]. This will enable the organization to understand IT Governance better and ensure it is efficient by using the recommended framework as a guideline. Currently, there are lack of methods that are available to assess the effectiveness of an organization's IT Governance and how it can contribute to the success of the IT projects or initiatives. On the other hand, the available ones are either not comprehensive enough or not able to address all the elements. A study conducted in North America shows that the manufacturing sector lost

Corresponding Author: Anusha Bhaskaran, Faculty of Business and Economics, University of Malaya, Malaysia. Email: anusha_09@yahoo.com 
$\$ 1.57$ billion from their revenue due to IT downtime and the time taken to recover data takes the longest i.e., 9.9 hours [10]. As discussed above, lack of IT Governance contributes to the failure of IT initiatives in any firm. Another research by the Butler Group found that any IT Initiative is only deployed within the IT Department without an alignment with the business. Tim Jennings, the research director of the Butler Group stated that the focus on IT Governance is less non-service industry and more susceptible to the poor returns on IT investment. This is not just an issue with IT but directly impacts the business [11].

\section{DEFINITION OF IT GOVENRNANCE}

IT Governance is the ability of the IT Management to work together with the top management in implementing IT Strategies in supporting organizational goals [12]. The board of directors and executives are accountable for the IT Governance. It comprises of the organizational structure, process and leadership. This is to ensure that the IT department aligns to the organization's objectives and strategies. In another definition, the board of directors, executives and IT Management exercises the IT Governance to control the implementation and formulation of IT Strategies to ensure that both the business and IT is aligned [12]. It is a foundation practiced widely to provide a structure to the organization to integrate the various elements within IT such as the resource, process and information that is required in implementing the designed strategy. Even though there are several definitions, the focus is still the same i.e., to align both IT and the business. It is crucial to investigate the IT system maintenance in ensuring that the organization's goals and strategies are met.

\section{IMPORTANCE OF IT GOVERNANCE}

Organizations with the highest performance are gaining $40 \%$ more profits from their IT investments when compared to their competitors [3]. Many organizations have heavily invested in IT. However, they encounter multiple challenges when it comes to directing the IT departments to create business value [14]. IT is an important factor for every organization to maintain their competitive advantage [14] [15] $[16][17][18] 9[19]$. It has become priority for the organizations to manage IT and use them as strategic drivers to achieve business goals [20].

There are many IT initiatives that failed to deliver significant value to the business on a yearly basis. There is a direct relation between the lack of IT governance and IT initiatives failures. This can be addressed by governing and managing IT via specific processes [21]. It is crucial to define the IT Governance for each organization because it has a positive impact on the firm's project performance which promotes business goals [22]. With a good IT investment, a highest performing firm gain $40 \%$ more than their competitors [3]. Previous research has shown that an organizations performance can be influenced by IT Governance [23][24]. IT Governance has a significant impact on innovation that enhances the performance of the firm [25]. However, there has been no research done in the past that was able to fit one single framework to all the organization [26]. Therefore, it is important to study the different characteristics of IT Governance before applying the practice to the studied organization

\section{IT GOVERNANCE AND ITS PEFOMANCE}

IT governance is a subset of the corporate governance and they are interrelated. Most of the concepts discussed in the former is derived to the later as well [34]. IT governance defines the accountability and decision rights to encourage the desirable attitude on the use of IT [3]. The degree of effectiveness of IT Governance determines the degree of impact of the form's overall performance. One of the main reasons for a destructive outcome of the IT investment is due to the ineffectiveness of IT Governance. The negative impacts include lack of innovation, financial losses and caused the various IT project to miss the deadlines [33]. IT Governance can be implemented via the various frameworks, standards and processes that has been identified [34]. For an organization to attain an effective IT Governance, the current situation needs to be analyzed and studied to meet the desired goal. The process of IT governance and other IT processes needs to be applied to measure the form's performance [33]. The performance can be measured through the four main outcomes of the IT Governance i.e., effective use of cost for IT, IT growth, asset utilization for IT and their business flexibility [3].

\section{IT INITIATIVE FAILURES}

There are many types of IT failures in an organization. In this case study, we will aim to study the 2 broad categories of IT failures i.e., failure of successfully rolling out a new project or system into production and service or business impact caused from a production system, application or network infrastructure. The latter is known of IT Operations failure due to inadequacies of standard operating procedures, non-standard solutions or even skillset to produce a good outcome. Likewise, an IT failure that is caused due to new deployments are due to the 
organization's dynamic capabilities to change or improve the current situation in terms of IT Resources for value delivery [27]. Regardless of whether it is an operation or new deployment failure, both results in service and business impact that cause financial losses such as a hardware failure that caused eBay \$2 million a day [28]. When such incidents take place, the organization aims to have a quick-win solution that has both short- and longterm implications. The organization tend to incur more cost to fix operations or to fix a project that is facing challenges. This was an evident in the case of Nike and Greyhound [29]. A fundamental view of such IT failures is due to the shortcomings in terms of competencies, knowledge an ability concerning processes of IT Governance. These failures have also been considered to an organizational failure [30]. The root cause of IT failures is due to the overestimation from the beginning of an IT initiative implementation [31].

\section{COMPONENTS OF IT GOVENANCE}

A framework with three important components for the IT Governance was developed previous study [32]. This framework includes structures, processes and relational mechanisms. Table 1 depicts the components of the framework with its description. All these three components are interrelated and cannot does not form IT Governance separately. The authors state that IT governance is not a separate entity but part of the enterprise governance. By implementing these three components, a firm can enable both the IT and business to fulfill their responsibilities and to be aligned to create business values.

\begin{tabular}{|c|c|}
\hline $\begin{array}{c}\text { Three IT } \\
\text { Governance } \\
\text { Mechanism }\end{array}$ & Description \\
\hline Structure & $\begin{array}{c}\text { Roles and responsibilities, Accountabilities, } \\
\text { IT Organizational structure, IT Strategic } \\
\text { committee and IT Steering committee }\end{array}$ \\
\hline Process & $\begin{array}{c}\text { Best practices (e.g., Cobit, SLA, BSC, ITIL, } \\
\text { IT alignment and maturity models) }\end{array}$ \\
\hline $\begin{array}{c}\text { Relational } \\
\text { Mechanisms }\end{array}$ & $\begin{array}{c}\text { Communication and collaboration between } \\
\text { the stakeholders, Cross functional business / } \\
\text { IT collaboration and trainings }\end{array}$ \\
\hline
\end{tabular}

Table 1: The three mechanism of IT Governance (adapted from Van Grembergen and De Haes, 2008.

$$
\text { p.25) }
$$

A leading global provider for knowledge, certification, assurance, and security, defined and further separated IT Governance into five main domains for an effective use of IT. These five focus areas are driven by stakeholder values. The first three are the drivers, namely, strategic alignment, resource management and performance measurement. While value delivery and risk management are the outcome.

\begin{tabular}{|c|c|}
\hline $\begin{array}{c}\text { Five domains } \\
\text { of IT } \\
\text { Governance }\end{array}$ & Description \\
\hline $\begin{array}{c}\text { IT Strategic } \\
\text { Alignment }\end{array}$ & $\begin{array}{c}\text { Alignment between the business objectives } \\
\text { and IT governance mainly to define, } \\
\text { maintain and validate IT propositions. }\end{array}$ \\
\hline $\begin{array}{c}\text { IT Resource } \\
\text { Management } \\
\text { Optitimal use of the IT investment on } \\
\text { infrastructure, information and } \\
\text { applications) to met the goals of the } \\
\text { organization. }\end{array}$ \\
\hline $\begin{array}{c}\text { IT } \\
\text { Performance } \\
\text { Measurement }\end{array}$ & $\begin{array}{c}\text { This domain focuses on tracking and } \\
\text { monitoring the IT deliverables, such as } \\
\text { balance scorecards and maturity models. }\end{array}$ \\
\hline $\begin{array}{c}\text { IT Value } \\
\text { Delivery }\end{array}$ & $\begin{array}{c}\text { The value proposition of the deliverables } \\
\text { from IT to ensure the that the business } \\
\text { requirements are met, benefits the strategy } \\
\text { and focuses on optimizing the IT cost. }\end{array}$ \\
\hline $\begin{array}{c}\text { IT Risk } \\
\text { Management }\end{array}$ & $\begin{array}{c}\text { Concentrates on the senior management's } \\
\text { risk awareness and their responsibilities in } \\
\text { managing it. }\end{array}$ \\
\hline
\end{tabular}

Table 2: The five domains of IT Governance (adapted

$$
\text { from ITGI, 2003) }
$$

According to the IT Governance Institute, IT Governance is applicable to any organization if there is a need for an alignment between IT strategy with the enterprise strategy by allocating the relevant resources to achieve the organizational goal. It helps to effectively manage the risks involved, realize the value projected from the IT investment, assess and measure the performance, to what extent they are achieving their objectives [33].

\section{CONCEPTUAL MODEL}

This concept paper aims to elaborate on how the combination of these three mechanisms and the five domains can improve implementation of an effective IT governance to influence the success of IT intiiatives. Figure 1 illustrates on how the combined mechanisms and domains would facilitate an effective IT governance.

The three mechanisms of IT governance acts as the overall governance in the IT department. In order to have an effective IT governance, the organization should first have the right organization structurewith the representative from each department. It is very important to define the roles and responsibilities of the various people involved in theIT. It needs to have a clear presentation and transparency to the organization. Apart from that, both the Chief Executive Officer (CEO) and the Chief Information Officer (CIO) needs to be alignedand accepted at the Executive board. With referenceto the framework by the authors, structures comprise of roles and responsibilities of the IT organizational 


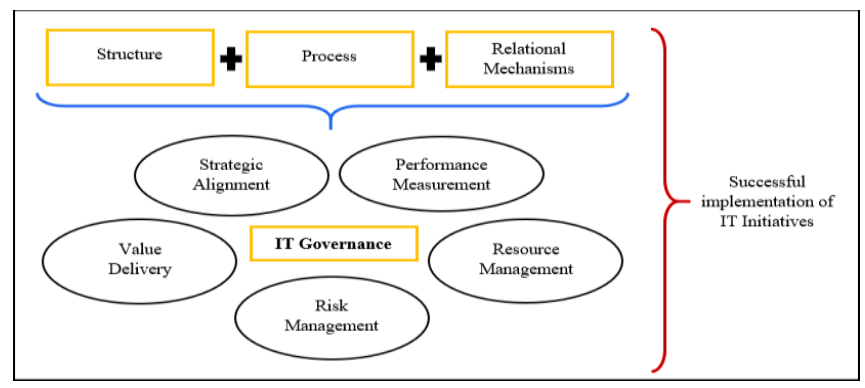

Figure 1: Conceptual Model

structure that includes the CIO, IT Strategy committee and IT Steering committee.

Once the structure has been established, it is important for the organization to focus on the best practices model that would suit the current situation in the IT department. Processes in the IT Governance framework refers to the strategic decision making and monitoring that are more engaged with the alignment between IT and business. Example of tools and processes used for the IT Governance are such as Val IT, balanced score card, COBIT and Service Level Agreement (SLA). The third component in the framework is the relational mechanism between the business and IT. It is a shared knowledge which is a two-way participation, communication and coloration between the two departments i.e. IT and business. This knowledge is gained through the IT executives' experience in the business and vice versa. The third component in the framework is the relational mechanism between the business and IT. It is a shared knowledge which is a two-way participation, communication and coloration between the two departments i.e. IT and business. This knowledge is gained through the IT executives' experience in the business and vice versa

As discussed above, the three components are crucial for the overall governance in an organization. This implementation of an effective IT governance can be exxecuted with these components. However, this concept paper, further examine the need to integrate the mechanisms with the five domains as itfurther fine tune the respective areas to ensure that the IT deliverables are successful. This provides a more refined implementation of an effective IT governance. IT Strategic Alignment ensures that the investment on IT adds value to the organization. Organization needs to consider if the current technology capabilities will align to their goals, strategies and needs, before investing in an IT solution. Despite knowing the importance of this domain, the executives are still facing challenges applying it. Some example to facilitate the alignment would be IT organizational structure, IT steering committees, SISP, an effective communication to give a mutual understanding between IT and business. An effective IT governance is reflected with an enhanced strategic alignment in order for them to continue working towards achieving the organizational goals by providing necessary support to the management.

The resource management domain is very crucial to ensure that the IT investment is aligned with the organizational goals. Resource management is not confined to people but also include tools, processes, hardware, infrastructure, application, and human skills where IT investment will then be translated to performance. This is to ensure that the organization's IT investment, knowledge, infrastructure and the IT functions are optimized. Determining and deploying the most appropriate IT capabilities is facilitated by IT Governance. Some of the process that aid with the resource management is such as SLA, PMBOK, effective communication and IT steering committees. Performance measurement is important to ensure that all planned actions related to IT initiatives has been executed successfully and for continuous improvement. It enables assessment on whether a project has met its objective, within schedule and budget, and if the infrastructure is sufficient for the users to work towards the strategic objectives. It also creates transparency to assess the IT capabilities and get early warnings for potential risks. It measures performance and value to the organization. IT Performance measurement contributes to the effectiveness of IT Governance.

One of the goals for IT Governance is to ensure the value delivery for the IT investments. This domain is important to meet the management's expectation. It is a form of contribution from IT to the organization's strategic goals. While delivering the value demands strategically, risk and impact to the IT activities on resources and business processes are considered. It includes defining roles and responsibilities to deliver IT capabilities, evaluating and comparing opportunities, continuous investment management, defining and monitoring performance 
metrics. It is important to ensure that there are continuous improvements on the operations and processes, rather than merely measuring the value in terms of financial performance. This is because measuring the value add for business from the investments is challenging as the benefits from IT is normally recognized as a business process.

Top management is more concerned and paying more attention to the internet-related risks. This is because there is a high possibility of external events interrupting with the business activities while working towards the organizational goals. Failure of the systems could lead to business losses, legal liability and damaged image and reputation of the firm. In IT, risk management is more related the IT assets protection, operational continuity and disaster recovery especially where IT infrastructure and information security are crucial. IT Governance is a form of managing risk. It is important for the top management to understand and recognize IT risks in ensuring that it is controlled. An effective IT Governance should validate and manage risk by placing necessary controls that would identify, eliminate, or transfer, monitor, trigger and mitigate any potential risks that could lead to IT failures. An effective IT Governance practice provides a better chance of managing risks. This can be done via mechanisms such as COBIT and Enterprise Risk Management (ERM).

\section{CONTRIBUTION}

The paper aims to demonstrate the importance of having IT Governance an organizatio to ensure the success in the IT initiatives led by the IT department. A substantial contribution of this concept paper to the literature is the definition of a simple, progressive, and scalable IT Governance implementaton. The paper is expected to contribute a minimum guideline for IT Governance practices with the integration of the 3 mechanism and 5 domains of $\mathrm{T}$ governance. Organizations could investigate on this areas in depth starting from the

(1) current IT Governance practice (2) Current initiatives in the IT department (3) Major challenges faced during the implementation and finally (4) identifying the criitcal success factors in implementating an effective IT governance for the success of IT iniatives.

\section{CONCLUSIONS}

It should be noted that even though IT initiatives are completed, it may not be totally considered has successful as there are potentials that the initiatives did not meet the allocated budget, estimated time or even the requirements set by the stakeholders. It is important to analyze if there is a lack of IT Governance practices that is affecting the success of IT initiatives in the respective organization. This is specifically in terms of the three main mechanisms (structure, process and relational mechanisms), and five focus areas (strategic alignment, resource successful implementation of the IT Initiatives.

\section{REFERENCES}

[1] Gormolski, B., Grigg, J. \& Potter, K. (2001), IT spending and staffing survey results.

[2] Gartner Group (2003), IT Spending: How do you stack up?

[3] Weill, P. (2004). Don't Just Lead, govern: How Top Performing Firms Govern IT. MIS Quarterly Executive, 3 (1), 1- 17.

[4] Brynjolfsson. Erik and Hitt, Lorin. [1993], "Is Information Systems Spending Productive? New Evidence andNew Results", The Proceedings of the 14th International Conference on Information Systems, Orlando, FL

[5] Dahlberg, T. \& Lahdelma, P. (2007), "IT Governance Maturity and IT Outsourcing Degree: An Exploratory Study", Proceedings of the 40st Hawaii International Conference on System Sciences.

[6] Tan, K. S., Eze, U. C., \& Teo, W. L. (2008). Information technology governance in the Malaysian electronics manufacturing industry. Communications of the IBIMA, 3, 138-144.

[7] Sambamurthy, V., \& Zmud, R. W. (2000). Research Commentary: The Organizing Logic for an Enterprise's IT Activities in the Digital EraA Prognosis of Practice and a Call for Research. Information Systems Research, 11(2), 105-114.

[8] De Haes, S. \& Van Grembergen, W. 2009, "An Exploratory Study into IT Governance Implementations and its Impact on Business/ITAlignment", Information Systems Management, vol.26, pp. 123-137.

[9] Peterson, R.R. (2004). Integration strategies and tactics for information technology governance. Strategies for Information Technology Governance IGI Global. (pp. 37-80)

[10] CA Technologies Research Report. (2010). http://m.softchoice.com/files/pdf/brands/ca/ACO D_REPORT.pdf

[11] Butler Group Research. https://www.marketresearch.com/ButlerGroup- v2731

[12] De Haes, S., W. Van Grembergen, and R. Debreceny. (2013). COBIT 5 and enterprise 
governance of information technology: Building blocks and research opportunities. Journal of Information Systems 27 (1): 307-324

[13] ITGI. (2008). IT Governance Global Status Report 2008. IT Governance Institute, ISBN 978-1-60420-064-5.

[14] Mithas, S., and Rust, R. T. (2016). How Information Technology Strategy and Investments Influence Firm Performance: Conjecture and Empirical Evidence. MIS Quarterly, 40(1), 223-245.

[15] Hardy, G. (2006). Using IT governance and COBIT to deliver value with IT and respond to legal, regulatory and compliance challenges, Information Security Technical Report, 11(1), 55-61

[16] ITGI. (2011) Global Status Report on the Governance of Enterprise IT (GEIT) - 2011. RollingMeadows, IL: IT Governance Institute.

[17] De Haes S, Van Grembergen W. (2015) Enterprise Governance of IT: Achieving Strategic Alignment and Value. Springer, New York.

[18] Couto, E. S., Lopes, M., and Sousa, R. D. (2015). Can IS/IT Governance Contribute for Business Agility? Procedia Computer Science, 64, 1099-1106.

[19] Sesay, A., and Ramirez, R. (2016). Theorizing the IT Governance role in IT sourcing research. In Proceedings of 22nd Americas conference in information systems (AMCIS 2016).

[20] Kappelman, L. A., Mclean, E., Johnson, V., and Gerhart, N. (2014). The 2014 SIM IT key issues and trends study, MIS Quarterly Executive, 13(4), 237-263.

[21] Asgarkhani, M., Cater-Steel, A., Toleman, M., and Ally, M. (2017). Failed IT projects: is poor IT governance to blame? In Proceedings of the 28th Australasian Conference on Information Systems (ACIS 2017). Australian Association for Information Systems.

[22] Sirisomboonsuk, P., Gu, V. C., Cao, R. Q., and Burns, J. R. (2018). Relationships between project governance and information technology governance and their impact on project performance. International Journal of Project Management, 36(2), 287-300.

[23] Kearns, G. S., and Sabherwal, R. (2006). Strategic alignment between business and information technology: a knowledge-based view ofbehaviors, outcome, and consequences, Journal of management information systems, 23(3), 129-162.

[24] Turel, O., and Bart, C. (2014). Board-level IT governance and organizational performance, European Journal of Information Systems, 23(2), 223-239.

[25] Vejseli, S., and Rossmann, A. (2017). The Impact of IT Governance on Firm Performance A Literature Review. In Proceedings of 21st Pacific Asia Conference on Information Systems (PACIS 2017), 41.

[26] Batyashe, T., and Iyamu, T. (2018). Architectural Framework for the Implementation of Information Technology Governance in Organizations. In Encyclopedia of InformationScience and Technology, Fourth Edition, 810-819, IGI Global.

[27] Winter, S.G., (2003). Understanding dynamic capabilities. Strategic Management Journal 24 (10),991-995.

[28] Li, K., (1999). Web glitch costing ebay \$2m a day. New York Daily News, June 12 (Saturday). http://www.nydailynews.com/archives/news/19 99/ 06/12/1999-0612_web_glitch_costing_ebay_2m_.html> (accessed 13.10.08.).

[29] Keil, M., Robey, D., (1999). Turning around troubled software projects: an exploratory study of the deescalation of commitment to failing courses of action. Journal of Management Information Systems 15 (4), 63-87.

[30] Goulielmos, M., (2005). Applying the organizational failure diagnosis model to the study of information systems failure. Disaster Prevention and Management 14 (3), 362-377.

[31] Hassan Issa \& Abu Hassan. (2008). Facilities of Information Technology in construction industry.2nd International Conference on Built Environmentin Developing Countries (ICBEDC 2008).

[32] Van Grembergen, W., and De Haes, S. (2008). Strategies and models for IT governance. IGI Global.

[33] ITGI. (2003). Board Briefing on IT Governance. 2nd Edition. Rolling Meadows, IL: IT Governance Institute, ISBN 1-893209-64-4. 